\title{
MODES OF EVOLUTION MAINLY AMONG MARINE INVERTEBRATES
}

\author{
An observational approach
}

\author{
by \\ H. J. MAC GILLAVRY \\ Geological Institute of the University of Amsterdam
}

Rapid advances, mainly in macro-molecular biology, make it necessary to return periodically to the sum total of observational information and to rebuild theory on evolution from the ground up. The possibility of incorporation of genetic information by viral infection, the non-deleterious nature of many pointmutations (which follows from phylogenetic estimates based on minimum mutation distances in specific proteins), and the relevance of the genetic environment to mutation (obvious from physico-chemical considerations), are but a few of the new data which may be mentioned. Less obvious, but equally necessary is a reappraisal of paleontologic information. An important gain in this field is the greater accessibility of the immense wealth of facts thanks mainly to the efforts of R. C. Moore (Treatise on Invertebrate Paleontology), J. Piveteau (Traité de Paléontologie), and of L. Hyman for the recent fauna (The Invertebrates). This paper will deal with paleontologic information obtained first from personal observation and secondly from literature.

Discussions on evolution should make a clear distinction between: a) the mechanism of evolution, b) observed evolutionary phenomena and successions, and c) the over-all panorama of faunal and floral evolution.

Appraisal of the over-all panorama is represented for instance by the visionary works of Teilhard de Chardin (see Simpson, 1960a, for a critical review). The emphasis is on evolution towards man, and not towards orchids or octopi; mammals and other vertebrates profit by reflection. Speculation in this field, whether obtained by revelation or otherwise, is bound to be rather airy, and should in any case be integrated with a thorough understanding of the two other aspects. We are still far removed from such understanding.

Ideas on the mechanism of evolution stem largely from information supplied by classical genetics (in- cluding ecological genetics) and from mathematical models based on such information. It is commonplace, but only partially correct, to say that genetic information is largely limited to a study of intraspecific variation and to the intra-specific evolution of local or insular races (the term local here includes the laboratory environments). Views on evolution beyond the species limit (whatever is meant by this), as derived from genetics, are obtained by a detour through theoretical and mathematical models 1). Another point, less frequently made, is that most genetic information is obtained from the study of non-marine animals and plants, and nowadays of equally nonmarine bacteria and virus. Macro-molecular biology, the new form of genetics, is rapidly beginning to contribute to the problem of evolution over far greater taxonomic distances. The contributions of paleontology at this level are of necessity inferential.

The observation of evolutionary phenomena and successions, on the other hand, is by its nature the field of study of paleontologists. Again there is some emphasis on vertebrates. This is understandable, for the vertebrates are possibly the only phylum which presents an intelligible succession of classes, complete even with a number of intermediate links. In the second place skulls and skeletons, by their very complexity, are far more expressive of evolutionary change than e.g., Foraminifera; in other words they provide a wealth of features that one can take hold of. On the other hand they are more rigidly integrated functionally, in particular under the strict requirements of terrestrial life, and thus have less tolerance for non-adaptive variation or evolution 2 ).

Most paleontologic information is based on a comparison of museum material derived from scattered localities, and the arrangement of this material in supposed phylogenetic lineages. A more rigid study based on sampling continuous sections, continuously 
fossiliferous and with non-varying lithologic facies is required. Such rigid temporal control is not easy to obtain. Common situations are: a) a limited number of fossiliferous beds is separated by barren intervals; b) a section, though continuously fossiliferous, shows many changes of facies or assemblage, so that single species or lineages are not found in uninterrupted sequence; finally the possibility of immigration and replacement by related forms should be kept in mind. Such studies have so far been few; well known examples are Brinkmann's studies of Kosmoceratidae and Trueman's studies of Gryphaea. The fact that Trueman's results have recently been questioned demonstrates that even then one should proceed with caution ${ }^{3}$ ). It is on such material that the use of numerical taxonomy will be of great phylogenetic importance. What, to my knowledge, is completely lacking, is a quantitative study of the entire fauna of such successions. A study of this kind should pay attention to the percentage of forms which do not show any evolutionary change.

During my work as an oil paleontologist I had the opportunity to study sections meeting these rigid requirements (the Tertiary marl formation of East Java, for instance). As an ardent student of evolution, moreover, I was continually on the watch for evidence of evolutionary change. The first conclusion to emerge was that such,instances are hard to find, and that many species do not show any evolutionary change at all. It may be contended that a more detailed and quantitative examination, for which there is no time in commercial work, would have disclosed many more cases, but such an opinion should not be based on a mere belief founded only on theoretical considerations. My studies were limited to Foraminifera, mainly benthonic forms, and to a lesser extent to Ostracoda. Foraminifera are of particular interest because many forms have a life-cycle with alternating generations: a diplont adult generation, which is often rare, gives rise by embryogenesis to an adult haplont generation which normally is the more frequent by far, and which by gametogenesis gives rise to zygotes from which again grow diplont adults 4). The diplonts have many nuclei; the haplonts have only one nucleus up to the moment of gametogenesis. The group therefore provides a unique genetical situation among animals: selection may be relaxed in the non-numerous diplont generation; in the far more frequent haplont generation, on the other hand, any selective advantage, unless extremely small or balanced by other factors, could lead to complete exclusion of unfavourable variants, leading to a situation without further selection $\left.{ }^{5}\right)$. As far as I know, the field of genetics of Foraminifera is still completely virgin. A useful compendium of many observed cases of evolutionary change among Foraminifera is provided by the Van der Vlerk jubilee volume (VoN Koenigswald e.a. ed., 1963). A drawback of the group is lack of expression: it will be difficult, in the case of fossil forms, to find forty characters, the minimum required for some multivariate methods.

The impressions acquired from my studies of wellsections are:

$a$. The great majority of species do not show any appreciable evolutionary change at all. These species appear in the section (first occurrence) without obvious ancestor in underlying beds, are stable once established, and disappear higher up without leaving any obvious descendants. Such "relay expansion" 8) is typical for the open market of neritic (sublittoral) benthos.

b. One or two species vary rather wildly without any time-sense. I have little experience of this type; it appears to be rather common among Liassic Lagenidae, although this family also contains some forms exhibiting sustained change (Barnaro, 1963). Notable recent examples among Gastropoda are the species of Neritina where one can hardly find two specimens with the same pattern. The genetics of these species should be exceedingly interesting; I do not know whether any work has been done on this problem ${ }^{7}$ ).

c. One species, after a diligent search, was thought to show a sustained change. This is a small Tritaxia in the Miocene of South Sumatra, which changes from triserial through biserial to uniserial in the adult. However, it was found that in the end it reverts to its original triserial form.

$d$. Only a few forms show really sustained change. This may be either change along divergent lines, as in the case of Bolivinoides (HutermanN, 1963) of which I have no personal experience, or the change may be directional, often with parallel development along independent branches. This is in particular the case among larger Foraminifera (MAC Gillavky, 1963). The evolution of these forms is composed of the successive introduction of new features, at first in part of a population (non-directional, saltative change) and the elaboration of the morphologic consequences of these new features by nepionic reduction (directional). The parallelism is therefore composite and consists of a non-directional introduction of the same succession of new features plus directional elaboration by nepionic reduction (acceleration, tachygenesis); divergent changes may be superposed upon this. The directional component occurs independently in lineages of the same genus; the entire 
complex may take place in the same, though not necessarily anatomically homologous manner, in different families.

Integrating these observations with other aspects of evolution, one may roughly distinguish three main modes of evolution. The distinction is of course overschematised.

1. Evolutionary radiation (explosive or eruptive evolution; the term adaptive radiation is not used because of its theoretical implications). This is the evolution of dashes ${ }^{8}$ ) at the bottom of a phylogenetic tree, which illustrates our lack of knowledge about the processes involved. Nor, as was pointed out by many authors, is it likely that geneticists are working with any material of this kind. Almost all discussion on the subject is speculative and based on a belief in evolution at all levels, justified by similarity of organisation and by cytologic and chemical similarity of recent forms. Presumably this evolution is extremely rapid. A good example is the simultaneous appearance in the Lower Cambrian of the Agnostida and other orders of the Trilobita. The argument here is similarity of anatomic and morphologic organisation.

2. Opportunistic adaptation. This is the normal mode of the open market ( $\alpha \gamma o \rho \alpha)$, where the ever changing synecologic influences now favour one form, then another, but where faunal equilibrium is maintained for a stretch of time between one disturbance and the next. This mode provides the possibility of using index fossils (species level) and permits the drawing of biozone boundaries. The word adaptation is introduced for want of a descriptive term, and because its use seems justified in this case. Again material evidence is practically non-existent. This type of evolution may likewise be extremely rapid. Or perhaps a certain form or genetic combination originates among a struggling population of such negligible numbers that no record remains. Once a successful type has been obtained the resulting form will spread explosively and become established and stable, until replaced, ousted, exterminated, or forced to a new sudden burst of opportunistic adaptation by some newcomer (relay expansion in the general sense used before). A good example is the index-fossil Homo sapiens: the search for ancestors of this species has been far more intensive than in any other case, yet the evidence is still meagre and controversial. Whole groups seem to be largely characterised by this mode: Trilobita, Brachiopoda, and even the Ammonoidea, which were probably largely pelagic and which then did not belong to the sublittoral benthos, although some may have lived close to the bottom. Species behaving in this manner constitute the majority of
Foraminifera among the Tertiary well-sample faunae of Indonesia. It is also likely that such forms constitute the bulk of the material studied by geneticists. What is studied, however, is the established form, hence the term wild-type. These species have not lost their potential for variation but they have incorporated mechanisms for stability and for the maintenance of wild-type, and tend to penalise change. Not investigated by geneticists is the obscure ancestor: thus it is not the evolution of such forms which is being examined but the stabilised result. It should be inter. esting to study the genetics of some rare struggling species which is not obviously a remnant of a once more powerful lineage now on the decline.

3. Sustained change. Lineages - the word species can not be aptly used here - which show sustained change constitute a minority among marine invertebrates. Hence the continuous use of the same few examples in the literature on evolution. In contrast with the two modes described previously, there is usually an abundance of material evidence. Sometimes, as in the case of the Miogypsininae, the entire history can be followed from the first appearance of the subfamily feature in a few aberrant individuals of an ancestral Rotalia-population. As has already been stated there may be an element of direction (orthogenesis in a descriptive sense). Moreover the same succession of changes and stages may be followed independently in different related lineages (program evolution), or even in not closely related groups (homoeomorphic parallelism, i.e., homoeomorphic stages attained not by different pathways but by the same path). In the case of related lineages there is some branching off of side lineages, which, however, tend to evolve in the same direction. Whether there is branching, and even some divergence with regard to other features, is therefore not relevant. Nor is it relevant whether directional evolution is rectilinear or not, for rate of change need not remain constant. Linearity also depends on the kind of scale used, or on the position of the origin before transformation to logarithms.

The word direction is often used incautiously, as in the tenet that natural selection is the only factor which gives direction to evolution. There is no direction involved in the phylogenetic introduction of a new type of aperture in Foraminifera, nor in the adoption of a pelagic mode of living by Daonella. Most evolution of marine invertebrates, the opportunistic mode, does not show any directional element, but a dimensionless diversification. The word direction should be used only when a change has true dimension. Furthermore a distinction can be made between 
a trend and a dimensional change along an axis of reference in diversification. The latter is most clearly expressed when one looks at one side of a sheaf of diverging lineages. For instance if size increase (Cope's rule) were a general trend, where do all the smaller animals in the world come from? Some of the smallest mammals and beetles that have ever existed are living right now. Size decrease is less conspicuous than size increase unless body length be plotted logarithmically. More often, however, diversification does not involve direction except in a vague way. A trend is a direction which involves the majority of related lineages of a group. Such a trend can be vague or of a more definite character; this admittedly involves a subjective judgment. The distinction is best illustrated by the example of size increase as compared with the more definite trend of nepionic reduction among larger Foraminifera. Trends should be established under rigid temporal control, i.e., from continuous sections.

Sustained change is not only well documented because of large numbers of available specimens but also, by its very nature, because it proceeds through a considerable length of time. Usually, in other words, the change is slow. The percentual rate of nepionic reduction per million years in Cycloclypeus is 7.5\% (calculated from Mac Gillavry, 1956 with Haldane's formula in Simpson, 1955, p. 15; calculation by compound interest gives 7.3\%). This is within the range of evolutionary rates of horse dentition (Simpson, 1955, p. 16), though on the high side of the range. The evolution which leads to Orbulina (pelagic Foraminifera) is exceptionally rapid, but still well documented 9 ).

Directional change within a lineage is important for stratigraphic dating, but the change is gradational and does not, as a rule, permit the drawing of sharp biozone boundaries, unless a precise threshold can be defined as in the case of Orbulina.

It is noteworthy that high values are obtained for the coefficient of variation in the case of evolving features among larger Foraminifera (values of the order of 12 to 20\%: MAC Gillavry, 1965, and unpublished data). Similar high values are also obtained in the case of Kosmoceratidae (average: 12.4\%; SxMpson, 1955, p. 68). The average value for evolving features of horse dentition is $6.4 \%$ (recalculated from Srmpson, 1955, p. 13, 74). In Microtus dentition, on the other hand, high values are obtained for those features which evolve most (GuTHRIE, 1965) ${ }^{10}$. All values, except those of the Kosmoceratidae, refer to features which are invariant with regard to individual growth.
Sustained, and in particular directional change, among marine invertebrates appears to be associated with environments of low faunal diversity, i.e., with few species which occur in a great number of specimens. Some caution is needed, because many paleontologic faunae of marine megafossils show a rather low diversity, much more so than would be expected from a knowledge of recent faunae. Nevertheless I believe the association to be true. Settlement of a new or relatively unoccupied ecologic niche thus may lead to sustained change, and not to evolutionary radiation, nor to opportunistic adaptation. This contrasts with the settlement of relatively unoccupied areas with diverse environments, where settlement does lead to evolutionary radiation.

The association is understandable: exceptional environments are specific and synecologic conditions are chiefly determined by other members of the same group.

The following examples illustrate the association: pelagic environment: Graptoloidea, pelagic Foraminifera;

deep-water benthos: Pygopidae (Brachiopoda);

limestone-belt with low diversity: larger Foraminifera of the Tertiary; Fusulinidae; Rudists;

brackish water: ?Cerithium.

In all cases the evidence for exceptional environment is direct, i.e., based on low diversity, and not inferentially on the ascribed facies. The limestonebelt of low diversity is an entirely different environment from coral reefs.

The program evolution of Graptoloidea may be less firmly established than formerly thought, but sustained change is obvious, and directional change likely. The taxonomic situation of pelagic Foraminifera is so chaotic at present that it is difficult to judge what is to be believed, but sustained change is clearly established, and the origin of Orbulina is a clearcut example of directional change. Larger Foraminifera are also found in faunae of greater diversity, but may then have been transported. Fusulinidae occur in richer faunae in the Pennsylvanian cyclothems of Kansas, but here again there is evidence of transport.

The converse of the "rule" of association is not true. The deep (hadal) sea is a refuge area at least in those cases where a species also has left a paleontologic record. The hypersaline environment is probably too impermanent to produce long range effects. But Lingula (brackish) and Dipnoi have survived in spite of such impermanence; nevertheless 
their evolutionary performance has been negligible for the past 150 million years or so. Here also the exceptional environment may have acted as a refuge.

Triassic Pteriidae became pelagic but did not persist for long. It is noteworthy that free-swimming Pelecypoda (various species of the families Pteriidae, Pectinidae, and Limidae) derive from a group (Anisomyaria) in which the main evolution has been towards an attached mode of living. The group is characterized by a directional reduction of the anterior adductor muscle; again many families (though not all nor always) occur in autochthonous faunae which are poor in species: Ostreidae (brackish), Mytilidae (mudflats), Bakewelliidae (e.g., Isognomon in extremely shallow water deposits of the Upper Jurassic, Boulonnais), Pinnidae (Cretaceous of New Mexico). However there may well be cases of directional change in normal environments: the "rule" is not a hundred percent law.

\section{SUMMARY}

Three modes of evolution are distinguished: 1 . evolutionary radiation, 2. opportunistic adaptation, 3. sustained change. Material evidence of evolution is almost non-existent in the first mode, very slight in the second. Opportunistic adaptation is characteristic of the sublittoral benthos; sustained change is associated with low faunal diversity.

\section{NOTES}

1) A few dangers of the theoretical detour may be pointed out: a) estimates of selection pressure depend greatly upon the mathematical model used (VAN VALEN, 1965); b) the Volterra-Gause principle, based on observation, but generalised on theoretical grounds, is contradicted by the diversity studies of Williams, (1964, chapter 9). Note that diversity parameter estimates depend on mathematical model, but diversity graphs not. The rule does not hold for Graptoloidea or pelagic Foraminifera; insect collectors will be familiar with many instances of coexistence: species of Aspidomorpha (Coleoptera, Cassidini) live together on Hypomoea plants in South Sumatra; Sorgenfrei's studies on Nassa, quoted by AGER (1963, p. 257) show coexistence with competition, but only one instance of complete exclusion of three species out of four. Species will not only differ morphologically but also ecologically, etc., but it has to be shown that these differences prevent mutual exclusion. Moreover, if there are no differences of this nature, the group will react as one population, so that there would not be any reason for the elimination of one of the constituent species except by accident.

2) Skeletons of birds, however, are much more stable. Perhaps the functional requirements in this case are so strict as to preclude further evolution once a functional arrangement has been acquired.

3) For relevant literature see BURNaby (1965) and PhILIP (1967). A reversed succession was independently observed by B. J. Romein on Gryphaea material from northern France (1953, unpublished master's thesis).

4) There seems now to be agreement that meiosis occurs just before embryogenesis in the few cases adequately studied, but it is dangerous to generalize, as Foraminifera differ greatly in life cycle.
5) The haplont generation must be indifferent to most allele differences studied in genetics: how else would one ever obtain normal Mendelian ratios or internally consistent linkage maps? Much selection among bacteria and virus, on the other hand, may be regarded as haplont selection. Certation as observed in the case of mammal sperm and of pollen tube penetration in plants, is a rather special case. It is not covered by Simpson's (1955, p. 138) definition of selection, which excludes selection towards a stable or fluctuating equilibrium, and which includes mutation pressure. Note, moreover, that PANDEY (1967) considers it possible that: "natural selection for $S$ specification mutation does not operate at the gametophytic level ...., but only at the sporophytic level." I am indebted to professor J. Heimans and professor F. Bianchi for information on certation.

0) The term "relay expansion" is here used in a general sense (Simpson, 1960b, p. 162) and not restricted to replacement of one form by another in the same ecologic niche (GlaessNer, 1965, p. 120). Thus it is here meant to include the extermination of snakes and groundbreeding birds on Jamaica by the introduction of the mongoose.

7) This variability is the more interesting since the beautiful colour patterns of many Gastropods, so valued by collectors, are not visible during the life of the animal. This, for instance, is the case in a number of Conus species. H. K. Mienis and H. E. Coomans inform me that the periostracum of Neritina (Vitta) virginea, the variability of which I have observed on Jamaica, is thin and transparent. However, species of the genus Neritina s.s. have a thicker periostracum and are equally variable. For the lack of genetical information on Neritina see ANDREWs (1941, p. 105). 
8) One is almost irresistibly tempted to pun.

9) During a discussion in Utrecht professor C. W. DRooGER and his group convinced me that I should place Orbulina in this category in spite of its more rapid evolution.

10) Guthrie's study distinguishes stable and rapidly evolving features. His study does not differentiate be- tween slowly and rapidly evolving features. In his paper Guthrie cites many instances of increase of relative variability of evolving or selected features. Note, however, that Guthrie obtains the greatest relative variability values for measurements which are small in absolute value: they would thus be more susceptible to lowering by class interval correction if classed in the same units as other features. In the second place it is not quite clear how some of these measurements were taken in the more primitive form.

\section{BIBLIOGRAPHY}

Ager, D. V., 1963: Principles of Paleoecology. McGraw Hill.

ANDREws, E. A., 1941: Neritina virginea, L., in Jamaica, B.W.I. The Nautilus 54, 3, pp. 98-106.

BARNARD, T., 1963: Evolution in certain biocharacters of selected Jurassic Lagenidae. Evolutionary trends in Foraminifera, pp. 79-92. Elsevier Publ. Cy.

Burnaby, T. P., 1965: Reversed coiling trend in Gryphaea arcuata. Geological Journal 4, 2, pp. 257-278, Liverpool.

GLAESSNER, M. F., 1965: Vorkommen fossiler Dekapoden (Crustacea) in Fisch-Schiefern. Senckenbergiana Lethaea 46a, pp. 111-122.

GUTHRIE, R. D., 1965: Variability in characters undergoing rapid evolution, an analysis of Microtus molars. Evolution 19, 2, pp. 214-233.

HiltermanN, H., 1963: Zur Entwicklung der BenthosForaminifere Bolivinoides. Evolutionary trends in Foraminifera, pp. 198-223. Elsevier Publ. Cy.

Koenigswald, G. H. R. Von, Emeis, J. D., Buning, W. L. \& WAGNER, C. W., editors, 1963: Evolutionary trends in Foraminifera, a collection of papers dedicated to I. M. VAN DER VlerR. Elsevier Publ. Cy.

Mac GillaVry, H. J., 1956: Mutation pressure, a possible cause of directional evolution in Cycloclypeus Carpenter (Foraminifera). Verh. Kon. Ned. Geol.-Mijnbouwk. Gen., Geol. Ser. 16. H. A. Brouwer jubilee volume, pp. 296-308.
- 1963: Phylomorphogenesis and evolutionary trends of Cretaceous orbitoidal Foraminifera. Evolutionary trends in Foraminifera, pp. 139-197. Elsevier Publ. Cy.

- 1965: Variability of larger Foraminifera. Part I: natural position of zero values. Proc. Kon. Ned. Ak. Wet. Amsterdam, ser. B 68, 5, pp. 335-355.

PANDEY, K. K., 1967: Origin of genetic variability: Combinations of peroxydase isozymes determine multiple allelism of the $S$ gene. Nature 213, no. 5077 , pp. 669 672.

PHILIP, G. M., 1967: Additional observations on the evolution of Gryphaea. Geological Journal 5, 2, pp. 329-338, Liverpool.

Simpson, G. G., 1955: The major features of evolution. Columbia Biological Series, XVII, 2d. printing. Columbia Univ. Press.

- 1960a: On the remarkable testament of the Jesuit paleontologist Pierre Temlard de Chardin. Scientific American, 202, 4, pp. 201-207.

$-1960 \mathrm{~b}$ : The history of life. In: The evolution of life, its origin, history, and future. Univ. of Chicago Press.

Van Valen, L., 1965: Selection in natural populations. III. Measurement and estimation. Evolution 19, 4, pp. 514-528.

Williams, C. B., 1964: Patterns in the balance of nature. Theoretical and Experimental Biology 3. Academic Press, London and New York. 